\title{
Excretion of Administered and Endogenous Photobilirubins in the Bile of the Jaundiced Gunn Rat
}

\author{
Mark S. Stoll, Eugene A. Zenone, and J. Donald Ostrow, Gastrointestinal \\ Section, University of Pennsylvania Medical Division, Veterans Administration \\ Hospital, Philadelphia, Pennsylvania 19104; Department of Biochemistry, \\ Bromley Hospital, Bromley, Kent BR2 9AJ, England
}

\begin{abstract}
A B S T R A C T Radiolabeled photobilirubins, prepared in vitro by anaerobic illumination of $\left[{ }^{14} \mathrm{C}\right]$ bilirubin, were injected intravenously into homozygous jaundiced Gunn rats with an external bile fistula. With the animals kept in darkness, the labeled photobilirubins were excreted rapidly in bile. Photobilirubins IA and IB were excreted primarily as unconjugated bilirubin, whereas photobilirubin II was excreted primarily as photobilirubin II and not converted into bilirubin. Bile of Gunn rats given no exogenous pigments, but undergoing phototherapy, contained a large proportion of photobilirubin II and, if collected in liquid nitrogen, traces of photobilirubins I; neither was found in bile when these rats were kept in the dark. Because there is prior evidence that these photobilirubins are isomers of bilirubin, these experiments indicate that the major mechanism of phototherapy is photoisomerization of bilirubin. Photobilirubin II is the unidentified major photoderivative described previously, whereas formation of photobilirubins IA and IB, and their reversion to bilirubin-IX $\alpha$, account for the remarkably increased output of the parent pigment during phototherapy.
\end{abstract}

\section{INTRODUCTION}

The formation of oxidative bilirubin derivatives by photosensitized singlet oxygen attack was initially postulated as an important mechanism for increased

This work was presented in part at Digestive Disease Week, Toronto, Ontario Canada, May 1977. (Gastroenterology. 72: 1180. [Abstr.]).

Address reprint requests to Dr. Ostrow, Gastroenterology Section, 111-G, Northwestern University Medical School, Veterans Administration Lakeside Hospital, Chicago, Ill. 60611. Dr. Stoll's present address is Clinical Chemistry Division, Clinical Research Centre, Middlesex HAl 3UJ, UK. Dr. Zenone's present address is Crozier-Chester Medical Center, Chester, Pa. 19105.

Received for publication 21 July 1980 and in revised form 18 February 1981. catabolism and clearance of bilirubin during phototherapy of the Gunn rat $(1-3)$. This is of considerable clinical relevance, since the Gunn rat is a good model for neonatal jaundice, which is now usually treated by phototherapy rather than the more hazardous exchange transfusion (4). However, it was soon appreciated that this mechanism could not explain excretion in bile of either unconjugated bilirubin per se $(3,5-8)$, or its major photoproduct (6), during phototherapy of the Gunn rat.

In the past $2 \mathrm{yr}$, we $(9)$ and Onishi et al. $(10,11)$ have reported the preparation and characterization of two pairs of polar photobilirubins, formed by anaerobic illumination of bilirubin dissolved in chloroform, dimethyl sulfoxide (9), or human albumin solution (10, 11). The properties of these photobilirubins suggested that they were bilirubin isomers, and that they corresponded to the major bilirubin derivatives formed during phototherapy of jaundice in vitro. Possibly related in vitro photoproducts have been reported by Lightner et al. (12-14), though direct comparisons are not possible since they were unable to isolate and purify their derivatives (16). This paper supports the role of the photobilirubins in the catabolism of bilirubin during phototherapy of the Gunn rat by showing that they are excreted rapidly in bile when given intravenously to the Gunn rat, and by showing that they appear endogenously in bile collected during phototherapy of these jaundiced animals. In view of prior in vivo studies $(6,8,10,11,13-16)$, this work suggests also that the major mechanism of increased bilirubin catabolism during phototherapy is probably photoisomerization, rather than photo-oxidation of bilirubin.

\section{METHODS}

Normal rat serum was prepared by centrifugation (900 $\mathrm{g}$ for $20 \mathrm{~min}$ ) of blood drawn by cardiac puncture of 450-600 $\mathrm{g}$ male Sprague-Dawley rats under light ether anesthesia. All chemicals were analytical reagent grade. 


\section{Preparation of bile pigments}

$\left[{ }^{14} \mathrm{C}\right]$ Bilirubin was prepared biosynthetically from $\left[4-{ }^{14} \mathrm{C}\right]$ aminolevulinic acid (New England Nuclear, Boston, Mass.) administered intravenously to Sprague-Dawley rats $(300$ $350 \mathrm{~g}$ ) with a bile fistula. The labeled bilirubin was isolated from bile, crystallized, and its specific activity determined as described by Ostrow et al. (17). Specific activities ranged from 1,600 to $5,550 \mathrm{dpm} / \mu \mathrm{g}$. The term "bilirubin," as used in this paper, refers to the natural IX $\alpha$ isomer in the $4 \mathrm{Z}, 15 \mathrm{Z}$ configuration (18).

Irradiated bilirubin. $\quad\left[{ }^{14} \mathrm{C}\right] \mathrm{Bilirubin}(500 \mu \mathrm{g})$, dissolved in $5 \mathrm{ml}$ chloroform containing a trace of EDTA, was purged with $99.99 \%$ nitrogen for $10 \mathrm{~min}$ and then illuminated with a mercury lamp for $5 \mathrm{~min}$ in the apparatus described previously (9) for preparation of photobilirubins. After illumination, the solution was evaporated to dryness in a stream of nitrogen at $40^{\circ} \mathrm{C}$, and the residue used for studies. Photobilirubins IA, IB, and II, both ${ }^{14} \mathrm{C}$-labeled and unlabeled, were isolated as described (9) by thin-layer chromatography of the products formed by anaerobic illumination of $\left[{ }^{14} \mathrm{C}\right]$ - or unlabeled bilirubin in chloroform or dimethyl sulfoxide solution, using the 100-W mercury spot lamp.

\section{Solutions of bile pigments for injection}

Bilirubin and irradiated bilirubin. The ${ }^{14} \mathrm{C}$-labeled pigment $(250-350 \mu \mathrm{g})$, dissolved in dimethyl sulfoxide $(200 \mu \mathrm{l})$, was added slowly with continuous mixing to $1.0 \mathrm{ml}$ normal rat serum, and the clear yellow solution $(1.2 \mathrm{ml})$ administered intravenously.

Photobilirubins I (A and/or B). Normal rat serum $(1.0 \mathrm{ml})$ containing a trace of EDTA, was added to photobilirubin(s) I, freshly prepared from $1 \mathrm{mg}$ unlabeled or $\left[{ }^{14} \mathrm{C}\right]$ bilirubin. After sonication for $5 \mathrm{~min}$ at $55 \mathrm{kHz}$ and $125 \mathrm{~W}$ in an ultrasonic cleaner (model B-220, Branson Ultrasonics Corp., Shelton, Conn.), the suspension was centrifuged at $900 \mathrm{~g}$ for $5 \mathrm{~min}$ to remove undissolved material, and the clear yellow supernate administered immediately intravenously.

Photobilirubin II. 80-180 $\mu \mathrm{g}$ photobilirubin II was dissolved in $1 \mathrm{ml}$ oxygen-free sodium phosphate buffer $(0.1 \mathrm{M}$, $\mathrm{pH}$ 7.40) containing $1 \mathrm{mM}$ disodium EDTA, and given intravenously without further preparation.

\section{Studies with Gunn rats}

Female, albino, homozygous, jaundiced Gunn rats, 250$400 \mathrm{~g}$, were purchased from the Animal Colony, Skin and Cancer Hospital, Temple University Health Sciences Center, Philadelphia, Pa. Under anesthesia with intraperitoneal pentobarbital $(5 \mathrm{mg} / 100 \mathrm{~g})$, polyethylene catheters (PE-10, Intramedic, Clay-Adams Co., New York, N. Y.) were placed in the femoral vein for infusions and injections, and in the common bile duct for collection of bile. The catheters were painted black and encased in aluminium foil to shield the emerging bile from light. The rats were then placed in Bollman-type restraining cages, and infused with $2.5 \%$ dextrose- $0.45 \% \mathrm{NaCl}(\mathrm{wt} / \mathrm{vol}$ ) at $1.8 \mathrm{ml} / \mathrm{h}$. For experiments to study the excretion of exogenous photobilirubins, the rats were maintained in darkness. To study the excretion of endogenously formed photoderivatives, the rats were placed under a phototherapy unit $(6,8)$ which contained six Daylite fluorescent lamps (General Electric Co., Cleveland, Ohio), that delivered $3.2 \mathrm{~mW} / \mathrm{cm}^{2}$ of radiant flux at the skin surface in the range of wavelengths from $400-500 \mathrm{~nm}$.

To attain a stable minimum biliary excretion of bile salts and bilirubin, bile flow was diverted for $15-18 \mathrm{~h}$ before commencement of the experiments (6). Bile, $1-2 \mathrm{ml} / \mathrm{h}$, protected from light, was collected in iced tubes or directly into liquid nitrogen as required. Collection tubes were changed every 1.5-2.0 $\mathrm{h}$ and kept on ice in the dark until analyzed on the same day. Serum was obtained by centrifugation of clotted blood withdrawn by incision of the tail vein during bile collections, and by cardiac puncture at the conclusion of each experiment.

\section{Analysis of serum and bile pigments}

Total diazo-reactive pigments were determined by the Michaelsson method (19), using $0.2 \mathrm{ml}$ of bile or extracts, and $25 \mu \mathrm{l}$ of serum. In serum, this was almost entirely unconjugated bilinubin $(6,8)$.

Unconjugated bilirubin in bile was determined by modified Folch solvent partition at $\mathrm{pH} 5.8$ (2), followed by thinlayer chromatography of the lower (chloroform) phase on silica gel $\mathrm{H}$ (Analtech, Inc., Newark, Del.), developed with chloroform-acetic acid, $100: 1$ by vol (20). The bilirubin band was removed and quantitated as described by Boonyapisit et al. (21), by in situ reaction with diazotized $p$-iodoaniline, followed by spectrophotometric determination at $530 \mathrm{~nm}$ of the azopigments extracted into $n$-butyl acetate. Losses were corrected by external standardization.

Total labeled photobilirubins and their derivatives were extracted from bile into the lower phase of a Folch solvent partition (2), modified as a single extraction at $\mathrm{pH}$ 3.0. The upper phase was then extracted twice with $4 \mathrm{vol}$ chloroform. The combined lower phases were washed with 1 vol water, and then taken to dryness under nitrogen at $40^{\circ} \mathrm{C}$. The pigment residue was dissolved in chloroform-methanol (2:1 by vol) and applied to $0.5-\mathrm{mm}$ thin layers of silica gel G (Analtech, Inc.). After development with chloroform-methanol-formic acid, $30: 3: 1$ by vol (2), pigment bands were eluted individually with chloroform-methanol-water, 40:9:1 by vol, except for the origin material, which was eluted with methanol-aqueous ammonia, $9: 1$ by vol.

Photobilirubin I was extracted from Gunn rat bile drained directly into liquid nitrogen during phototherapy. After addition of chloroform ( $4 \mathrm{vol})$ containing 0.1 vol acetic acid and a trace of disodium EDTA, pigments were extracted by vigorous shaking and then centrifugation at $900 \mathrm{~g}$ for $2 \mathrm{~min}$. The chloroform layer was washed twice with 1.2 vol water, and evaporated to dryness under nitrogen at $40^{\circ} \mathrm{C}$. The residue, dissolved in chloroform-methanol ( $2: 1$ by vol), was applied to 0.5-mm thin layers of Camag, Inc. (New Berlin, Wis.) silica gel D-O containing disodium EDTA (100 mg/60 g dry gel), and developed with chloroform-methanol-water (40:9:1 by vol). The photobilirubin I band was eluted with the development solvent.

Radioassay. Eluates of bile pigments were placed in scintillation vials and dried under nitrogen at $40^{\circ} \mathrm{C}$. Azopigment extracts were first decolorized by illumination with the mercury lamp after addition of 1 drop $30 \% \mathrm{H}_{2} \mathrm{O}_{2}$, and then similarly taken to dryness. These residues, bile $(200 \mu \mathrm{l})$, or serum $(50 \mu \mathrm{l})$, were blended with $0.2 \mathrm{ml}$ of $1 \mathrm{M}$ hyamine in methanol (New England Nuclear, Boston, Mass.), and then $3.0 \mathrm{ml}$ ethanol, $10 \mathrm{ml}$ diphenyloxazole $(8 \mathrm{~g} / \mathrm{liter})$ in toluene, and 2 drops of glacial acetic acid were added sequentially. Counting was performed to $10 \mathrm{~K}$ in a Packard Tricarb model 2650 liquid scintillation spectrometer at $87 \%$ efficiency, as determined by an external standard and channel ratios.

\section{RESULTS}

Excretion of exogenous photobilirubins by Gunn rats

Injection of labeled bilirubins (Figs. 1 and 2). Two test rats were each injected with $1.2 \mathrm{ml}$ of serum con- 


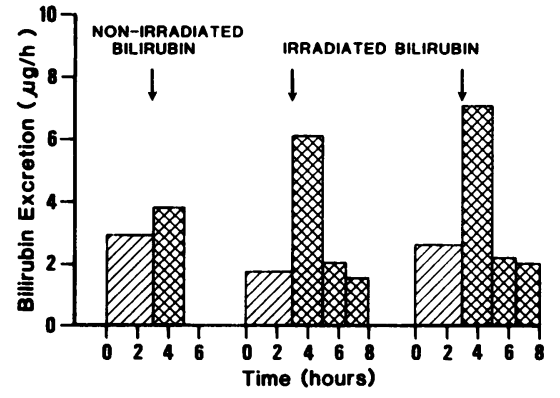

FIGURE 1 Excretion of bilirubin in the bile of Gunn rats given irradiated or unirradiated $\left[{ }^{14} \mathrm{C}\right]$ bilirubin. After a 3-h base-line collection period, each animal received, as a single bolus, $350 \mu \mathrm{g}$ i.v. of the labeled pigment, dissolved in $1.2 \mathrm{ml}$ normal rat serum. Animals kept in dark throughout.

taining $350 \mu$ g irradiated $\left[{ }^{14} \mathrm{C}\right]$ bilirubin, and one control rat with a comparable solution of unirradiated $\left[{ }^{14} \mathrm{C}\right]$ bilirubin $(5,500 \mathrm{dpm} / \mu \mathrm{g}$ sp act for each). Thinlayer chromatography revealed that the irradiated bilirubin contained $81.7 \%$ bilirubin, $6.1 \%$ photobilirubins I, and $12.2 \%$ miscellaneous photoproducts. The injections raised the serum bilirubin levels by $<23 \%$ above base-line values.

In the two test rats, 76 and $96 \%$ of the label injected as nonbilirubin photoproducts were recovered in the bile excreted during the next $5 \mathrm{~h}$. Of this, 19 and $24 \%$ were converted to bilirubin, resulting in an increase in bilirubin outputs during only the 1 st $2 \mathrm{~h}$ to 2.5 and 3.0 times the base-line excretion rates (Fig. 1). In the control rat, only $0.6 \%$ of the injected ${ }^{14} \mathrm{C}$ was excreted, of which only $4 \%$ was bilirubin, and bilirubin excretion increased by only one-third. During the 1 st $2 \mathrm{~h}$ after injection, the specific activity of the bilirubin in the bile of the two test animals was 14 and 17 times that of the control animal, with values 70 and $86 \%$ of the

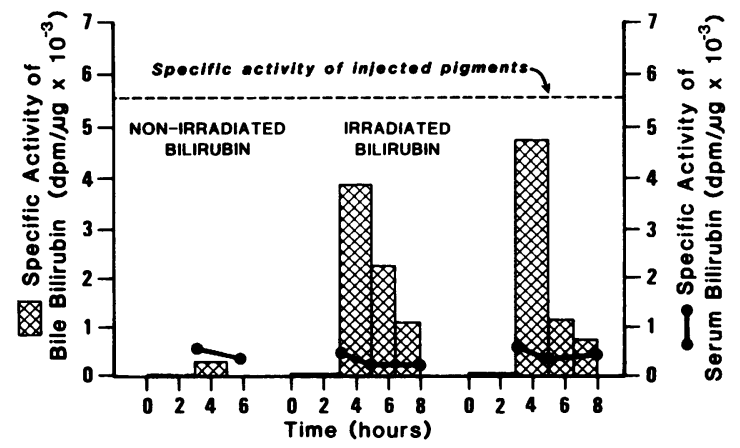

Figure 2 Specific activity of bilirubin in the bile of Gunn rats given irradiated or unirradiated $\left[{ }^{14} \mathrm{C}\right]$ bilirubin $(5,500 \mathrm{dpm} /$ $\mu \mathrm{g}$ sp act). Animals are the same as in Fig. 1. For each collection period, the specific activity of the bilirubin isolated from the bile (bars) is compared with the specific activity of the relevant serum bilirubin, and the injected bilirubin. specific activity of the administered $\left[{ }^{14} \mathrm{C}\right]$ bilirubins, but declined rapidly thereafter (Fig. 2). Moreover, the specific activity of the initial bile bilirubin of the test animals was at least 10 times greater, whereas that of the control animal was less, than the specific activity of the corresponding serum bilirubin.

Injection of unlabeled photobilirubins I (Fig. 3). During the lst $h$ after intravenous administration to a single Gunn rat of $1.0 \mathrm{ml}$ rat serum containing 100 $\mu \mathrm{g}$ photobilirubins I, excretion of diazo-reactive compounds increased to 5.7 times, and of bilirubin to 148 times their respective base-line outputs in bile. These outputs returned to base-line values by $3 \mathrm{~h}$ after injection. By this time, correcting for the base-line excretion, $49 \%$ of the injected diazo-reactive pigment was recovered in the bile, with $>90 \%$ of this in the form of bilirubin. During the 1st h, two-thirds, and during the 2 nd and $3 \mathrm{rd} \mathrm{h}$, all the excess diazo-reactive compounds excreted were represented by bilirubin. The succeeding experiment with ${ }^{14} \mathrm{C}$-labeled photobilirubins I showed that the injected material contained a proportion of bilirubin and traces of other polar products.

Injection of labeled photobilirubin IA and IB individually (Table I). One Gunn rat each was given 1.0 $\mathrm{ml}$ i.v. normal rat serum containing a purified preparation of $\left[{ }^{14} \mathrm{C}\right]$ photobilirubin IA or IB, isolated by preparative thin-layer chromatography of irradiated $\left[{ }^{14} \mathrm{C}\right]$ bilirubin. However, rechromatography of the administered pigments revealed that, during elution, evaporation, and dissolution in serum, all but $22.4 \%$ of photoisomer IA and $10.9 \%$ of isomer IB had reverted to $\left[{ }^{14} \mathrm{C}\right]$ bilirubin and $<2 \%$ of other polar products.

Of the total administered ${ }^{14} \mathrm{C}$-pigments, $46.8 \%$ of preparation IA and $61.8 \%$ of preparation IB were re-

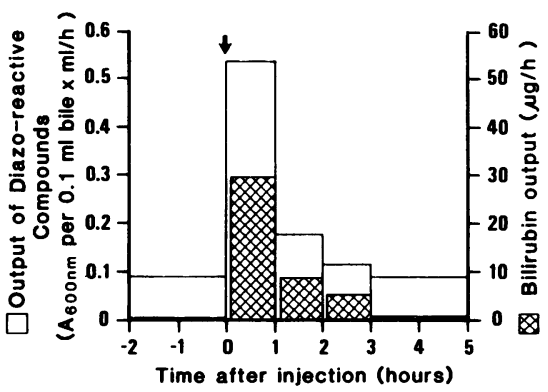

FIGURE 3 Excretion of bile pigments after administration of a preparation of photobilirubins I to a Gunn rat. Photobilirubins $\mathrm{I}, 100 \mu \mathrm{g}$, were given as an intravenous bolus (arrow) at time 0 , after a 2 -h base-line bile collection. Output of diazo-reactive compounds (left scale, open bars), determined by the Michaelsson method (19), is expressed as $\mathrm{A}_{600 \mathrm{~nm}}$ per $0.1 \mathrm{ml}$ bile $\times$ bile volume $(\mathrm{ml} / \mathrm{h})$. It is scaled to be roughly equivalent to the bilirubin output (right scale, shaded bars), were all the diazo-reactivity due to bilirubin (for bilirubin, diazo $A_{600}$ per $0.1 \mathrm{ml}$ bile $\times 9.61=$ micrograms bilirubin per $0.1 \mathrm{ml}$ bile). 
TABLE I

Administration of $\left[{ }^{14} \mathrm{C}\right]$ Photobilirubins IA and IB Intravenously to Gunn Rats

\begin{tabular}{lcc}
\hline & \multicolumn{2}{c}{ Preparation injected } \\
\cline { 2 - 3 } & $I A$ & $I B$ \\
\hline Pigment administered, $\mu g$ & 105.6 & 80.3 \\
As photobilirubin, $\mu \mathrm{g}$ & 23.7 & 8.75 \\
As photobilirubin, \% & 22.4 & 10.9 \\
Specific activity, $d p m / \mu g$ & 1,606 & 1,606 \\
Pigment recovered in bile: & & \\
During first 2 h & & \\
Total, \% injected ${ }^{14} \mathrm{C}$ & 30.7 & 43.5 \\
{$\left[{ }^{14}\right]$ Bilirubin, $\mu \mathrm{g}$} & 16.3 & 5.7 \\
$\%$ Excreted ${ }^{14} \mathrm{C}$ & 50.1 & 16.3 \\
$\%$ Injected photobilirubin & 68.8 & 65.4 \\
Specific activity, $d p m / \mu g$ & 1,201 & 1,197 \\
During $24 \mathrm{~h}$ & & \\
Total, \% injected ${ }^{14} \mathrm{C}$ & 46.8 & 61.8 \\
{$\left[{ }^{14} \mathrm{C}\right]$ Bilirubin, $\mu \mathrm{g}$} & 16.8 & 5.84 \\
$\%$ Excreted ${ }^{14} \mathrm{C}$ & 34.0 & 11.8 \\
\% Injected photobilirubin & 70.9 & 66.8 \\
Serum bilirubin specific & & \\
activity, $d p m / \mu g$ & 14 & 11 \\
\hline
\end{tabular}

Each preparation, dissolved in $1.0 \mathrm{ml}$ normal rat serum given as an intravenous bolus to one rat at time 0 . Animals kept in dark throughout study.

covered in the bile during the subsequent $24 \mathrm{~h}$, of which approximately two-thirds was excreted during the 1 st $2 \mathrm{~h}$. Of the radioactivity administered as photoisomer per se, approximatey two-thirds was recovered in the bile as $\left[{ }^{14} \mathrm{C}\right]$ bilirubin, virtually all of which was excreted during the 1 st $2 \mathrm{~h}$. The specific activity of the $\left[{ }^{14} \mathrm{C}\right]$ bilirubin in the bile of each rat was approximately three-fourths that of the administered pigment, but almost 100 times that of the corresponding serum bilirubin. None of the administered photoisomer was recovered unchanged. The label not recovered as bilirubin was present as polar compounds that were not further characterized but were chromatographically similar to those described in Gunn rat bile during phototherapy (6).

Injection of unlabeled photobilirubin II. Two Gunn rats each received a bolus of $180 \mu \mathrm{g}$ photobilirubin II dissolved in $1.0 \mathrm{ml}$ phosphate buffer. During the 1st 50 min after injection, output of diazoreactive material in bile increased to 2.6-2.8 times base-line values, but returned nearly to base line thereafter (Table II). The azopigments formed with the postinjection bile sample exhibited the same atypical, orange-red color given by diazotization of photobilirubin II (9). In both animals, inspection of the thinlayer chromatograph of the Folch extracts of the postinjection bile revealed a marked outpouring of a yellow, nonfluorescent pigment, $C-9$, that was not visible in the
TABLE II

Excretion of Diazo-reactive Compounds in the Bile after Bolus Administration of Photobilirubin II to Gunn Rats

\begin{tabular}{lccc}
\hline & \multicolumn{3}{c}{ Output of diazo-reactive compounds* } \\
\cline { 2 - 4 } Bile collection & Basal & $0-50 \mathrm{~min}$ & $50-130 \mathrm{~min}$ \\
\hline & \multicolumn{3}{c}{$A_{800 \mathrm{~mm}} / 0.1 \mathrm{ml} \mathrm{bile} \times \mathrm{mllh}$} \\
Rat A & 0.104 & 0.268 & 0.115 \\
Rat B & 0.054 & 0.150 & 0.060 \\
\hline
\end{tabular}

At time 0 , each rat received $180 \mu$ gi.v. photobilirubin II dissolved in $1.0 \mathrm{ml} 0.1 \mathrm{M}$ sodium phosphate buffer, $\mathrm{pH}$ 7.4,

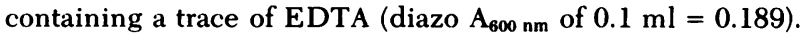
Animals kept in the dark throughout.

* Diazo reaction performed with the method of Michaelsson. For reference bilirubin standard, $A_{6100 \mathrm{~nm}} \times 9.61 \pm$ micrograms bilirubin $/ 0.1 \mathrm{ml}$ bile.

basal bile. Pigment C-9 corresponded in appearance and $R_{f}$ value to the injected photobilirubin II, chromatographed concurrently, either after dissolution directly in chloroform, or after addition to basal bile followed by Folch extraction. The initial postinjection bile also exhibited moderate increments in pigments C-5 (dihydroxybilirubin) and C-14 (the brownish, poorly soluble origin material), along with small increases in C-1 (bilirubin), the hydroxybilirubins (C-6, -7 , and -13 ), and biliverdin (C-11). Of these products, traces of C-7 and C-11 contaminated the administered photobilirubin II, whereas only bilirubin, C-5, -6, -7 , and -14 were present in basal bile. A significant increase in C-14 occurred during Folch extraction of a mixture of photobilirubin II and basal bile, suggesting that this material was in large part produced by chemical degradation of photobilirubin II during extraction of bile.

Injection of labeled photobilirubin II as a bolus (Table III). After administration of $1.0 \mathrm{ml}$ of a buffered solution of $\left[{ }^{14} \mathrm{C}\right]$ photobilirubin II $(79 \mu \mathrm{g}$, sp act 1,606 $\mathrm{dpm} / \mu \mathrm{g}) 90.3 \%$ of the radioactivity was excreted in the bile of the Gunn rat in $3 \mathrm{~h}$, almost all in the 1st h. On Folch extraction at $\mathrm{pH} 3.0,12.1 \%$ of the radioactivity of the bile collected during the 1 st $h$, remained in the upper, aqueous phase. Chromatography of the lower phase revealed a pattern similar to that seen with the unlabeled pigment, with half the excreted label recovered as unchanged photobilirubin II (C-9) and 6.5\% as dihydroxybilirubin (C-5). Small amounts of ${ }^{14} \mathrm{C}$ appeared also in the other dihydroxyderivatives (C-6 and -7) and the immobile brown pigment at the origin (C-14). In contrast to the results after injection of photobilirubins IA or IB, $<0.2 \%$ of the injected photobilirubin label was recovered as bilirubin. The remaining one-fourth of excreted radioactivity was scat- 
TABLE III

Excretion of Labeled Bile Pigments after Bolus Administration of $\left[{ }^{14} \mathrm{C}\right]$ Photobilirubin II to a Gunn Rat

\begin{tabular}{lccr}
\hline & R, value & $\begin{array}{c}\text { Quan- } \\
\text { tity }\end{array}$ & $\begin{array}{r}\text { Percent } \\
\text { injected } \\
\text { pigment* }\end{array}$ \\
\hline & & $\mu g$ & \\
Total bile samples & & & \\
$0-1$ h & & 67.8 & 85.8 \\
1-2 h & 2.7 & 3.4 \\
2-3 h & 0.8 & 1.0 \\
Pigments in 0-1 h bile & & & \\
Folch upper phase & - & 8.2 & 12.1 \\
C-1, bilirubin & 0.91 & 0.12 & 0.2 \\
C-5, dihydroxybilirubin & 0.58 & 4.4 & 6.5 \\
C-6/7, dihydroxybilirubins & $0.43 / 0.32$ & 0.97 & 1.4 \\
C-9, photobilirubin II & 0.24 & 35.2 & 51.9 \\
C-14, original material & 0.00 & 1.2 & 1.8 \\
Remaining bands & - & 17.7 & 26.1 \\
\hline
\end{tabular}

$\left[{ }^{14} \mathrm{C}\right]$ Photobilirubin II, $79 \mu \mathrm{g}, 1,606 \mathrm{dpm} / \mu \mathrm{g}$ sp act, dissolved in $1.0 \mathrm{ml} 0.1 \mathrm{M}$ sodium phosphate buffer, $\mathrm{pH} 7.4$, administered intravenously at time 0 to a Gunn rat with a bile fistula, kept in the dark throughout the study.

* For pigments in 0-1-h bile, values are for excreted pigment. \$ Thin-layer chromatography of Folch lower phase extract performed as in reference 6 , with designated bands eluted and quantitated by radioassay.

tered among the other pigment bands, which have not yet been identified.

Infusion of unlabeled photobilirubin II (Table IV). A single Gunn rat, kept in the dark, was infused with photobilirubin II in buffer at a rate of $45 \mu \mathrm{g} / \mathrm{h}$, approximately the normal rate of bilirubin production in the Gunn rat (22). As revealed by visual comparison of the chromatograms, the bile collected before infusion contained no detectable C-9 and only traces of bilirubin. With infusion of photobilirubin II for $3 \mathrm{~h}$, the output of diazo-reactive materials increased to twice the base-line rate, the C-9 bands became intensely yellow, and a slight increase in bilirubin was detected also. After $3 \mathrm{~h}$, with the infusion of photobilirubin II continued, phototherapy was administered. During this period, excretion of C-9 appeared qualitatively undiminished, but there was a further increment in diazo-reactivity to approximately three times that of base line, largely due to a markedly enhanced output of bilirubin. After $4.75 \mathrm{~h}$, with phototherapy continued, the photobilirubin infusion was halted; this resulted in a marked decrease in the excretion of C-9, while the output of bilirubin remained high. Throughout the study, less striking changes in the output of C-5 and C-14 paralleled those of C-9.

Identification of endogenously formed photobilirubins excreted in bile during phototherapy. Pooled bile, collected on ice and in the dark from two Gunn rats exposed to phototherapy for $9 \mathrm{~h}$, was subjected to sequential Folch partition at $\mathrm{pH} 7$ and 3, as described previously $(2,6)$. Chromatography of the lower phases confirmed prior reports $(2,6)$ that the $\mathrm{pH} 7$ extract contained only bilirubin and porphyrins, whereas the $\mathrm{pH} 3$ extract contained bilirubin and C-9 as the major components. The endogenous C-9 photopigment was eluted from the chromatogram and compared with authentic photobilirubin II, prepared in vitro by anaerobic illumination of bilirubin in dimethyl sulfoxide (9). The two compounds, studied simultaneously, exhibited identical properties as follows: $(a)$ visible absorption maxima at $441 \mathrm{~nm}$ in chloroform and $429 \mathrm{~nm}$ in methanol: $(b)$ rapid and almost complete reversion to bilirubin on anaerobic illumination in chloroform; (c) reaction with diazotized sulfanilic acid in methanol to yield an atypical, orange-red azopigment; $(d)$ stability in chloroform, methanol, dimethyl sulfoxide and $0.1 \mathrm{M} \mathrm{NaOH}$, as long as light and oxygen were excluded; $(e)$ formation of poorly soluble brown products (C-14) on exposure to acetic acid or Folch extraction at $\mathrm{pH} 3.0 ;(f)$ formation of a plum-red color, but no biliverdin, on reaction with 2,3-dichloro-5,6-dicyano-

TABLE IV

Excretion of Pigments in Gunn Rat Bile during Infusion of Photobilirubin II*

\begin{tabular}{|c|c|c|c|c|c|}
\hline Collection period & $-1.5-0 \mathrm{~h}$ & $0-1.5 \mathrm{~h}$ & $1.5-3.0 \mathrm{~h}$ & $3.0-4.75 \mathrm{~h}$ & $4.75-6.0 \mathrm{~h}$ \\
\hline Photobilirubin II infusion & No & Yes & Yes & Yes & No \\
\hline Phototherapy & No & No & No & Yes & Yes \\
\hline \multicolumn{6}{|l|}{ Output of diazo-reactive } \\
\hline compounds & 0.091 & 0.126 & 0.172 & 0.251 & 0.260 \\
\hline Photobilirubin II excreted in bile $\S$ & None & $4+$ & $4+$ & $4+$ & $2+$ \\
\hline Bilirubin in bile $\$$ & Trace & $1+$ & $1+$ & $4+$ & $4+$ \\
\hline
\end{tabular}

* Photobilirubin II infused in phosphate buffer (see Table II) at $45 \mu \mathrm{g} / \mathrm{h}$.

\$ As in Table II, diazo-reactive compounds expressed as $A_{600 ~ n m} / 0.1 \mathrm{ml} \mathrm{bile} \times \mathrm{ml} / \mathrm{h}$; for bilirubin, $A_{600 \mathrm{~nm}} \times 9.61=\mu \mathrm{g}$ bilirubin per $0.1 \mathrm{ml}$ bile.

$\S$ Semiquantitative assessment from visual intensity of band on thin layer chromatography plate. 
$p$-benzoquinone in dimethyl sulfoxide ( $g$ ) identical $\boldsymbol{R}_{\mathrm{f}}$ values on thin-layer chromatography in three different solvent-gel systems (9).

Because the unstable photobilirubins I were not identified in the above study, we attempted to stabilize this pigment in bile by collecting the bile directly into liquid nitrogen in the dark, and extracting and chromatographing the bile pigments after only $2 \mathrm{~h}$ of bile collection. Phototherapy bile thus obtained contained abundant bilirubin and photobilirubin II, but also small amounts of a pigment, with the appropriate $R_{f}$ value, that shared all the properties described previously (9) for photobilirubin I. No such pigment was found in the bile of an unilluminated Gunn rat, collected and processed in identical fashion.

\section{DISCUSSION}

In 1971, McDonagh (1) produced evidence that photooxidation via autosensitized addition of singlet oxygen might constitute an important mechanism of bilirubin photodegradation. However, the major photoproducts predicted by this mechanism, 5,5'-diformyldipyrromethane and propentdyopents (23), were not found among the bilirubin derivatives excreted in Gunn rat bile during phototherapy (6), and the two major pigments excreted during phototherapy, bilirubin itself and a yellow, acid-labile, diazo-positive pigment called C-9 (6), were not reproducible by photo-oxidative singlet oxygen reactions. McDonagh (7) subsequently postulated that photoisomerization might produce tetrapyrroles that were sterically incapable of the internal hydrogen bonding of bilirubin IX $\alpha$ (18), and thus would be sufficiently polar to be excreted in bile without conjugation.

Recently, Lightner et al. $(13,14)$ reported the formation of three photobilirubins during illumination of bilirubin in a variety of solvents under aerobic conditions, but were unable to purify these derivatives because of their thermal instability (16). By illumination of bilirubin under anaerobic conditions that precluded oxidative reactions, we (9) and Onishi et al. (10, 11) produced and purified chromatographically a pair of unstable (I) and a pair of stable (II) photobilirubins. All the reported photobilirubins were more polar than the parent bilirubin IX $\alpha$, being easily soluble in water and methanol. They also reverted to bilirubin IX $\alpha$ when reilluminated briefly with visible light, attaining a photoequilibrium in which $<10 \%$ of the pigment was in the form of the photobilirubins. Mass spectrometry $(9,24)$ and azopigment analysis $(10,11)$ indicated that these derivatives were neither photoadducts nor the III $\alpha, \operatorname{XIII} \alpha, \operatorname{IX} \beta, \operatorname{IX} \gamma$, or IX $\delta$ isomers of bilirubin. Based on these properties, all three groups postulated that the photobilirubins resulted from configurational (geometric, $\mathrm{Z}$ to $\mathrm{E}$ ) photoisomerization at the $\Delta 4,5$ and/ or $\Delta 15,16$ methene bridges of bilirubin IX $\alpha$, which are normally in the $\mathrm{Z}$ configuration (18). Unfortunately, these photobilirubins have not yet been prepared with sufficient quantity or stability to permit nuclear magnetic resonance spectroscopic analysis, which could provide rigorous proof of these tentative structural assignments.

All three groups have reported that the less polar photobilirubins (our IA and IB) are thermally unstable in the dark, reverting rapidly to bilirubin, especially in polar solvents (e.g., bile) $(9-11,14)$. The reversion is retarded greatly by $1 \mathrm{mM}$ EDTA, serum albumin, and nonpolar solvents such as chloroform (9-11). These properties suggested that formation and excretion of these polar photobilirubins could explain the enhanced appearance of bilirubin IX $\alpha$ in bile during in vivo phototherapy (8). Strong indirect evidence for this thesis has been the demonstration that the photobilirubins accumulate in the serum of Gunn rats (16) and human infants $(11,15)$ during phototherapy, and correlate temporally with the enhanced excretion of bilirubin IX $\alpha$ in their bile (15). Moreover, when photobilirubinenriched serum from an illuminated donor Gunn rat was administered intravenously to another Gunn rat kept in the dark, large amounts of the natural bilirubin IX $\alpha, Z, Z$ isomer appeared in the bile of the recipient rat (16).

Our present studies with purified photobilirubins prepared in vitro provide more direct evidence of their role in this phenomenon. Administration to unilluminated Gunn rats of a mixture of photobilirubins, or of isolated photobilirubins IA and IB, led to $>100$ fold increments in bilirubin IX $\alpha, Z, Z$ in their bile. Unfortunately, during the isolation and dissolution in serum of the photobilirubins IA and IB, the majority reverted to bilirubin and a small proportion degraded to other polar products. Moreover (Table I), a larger proportion of the ${ }^{14} \mathrm{C}$ excreted was in the form of other polar products, presumably formed by metabolism or degradation of some of the administered photobilirubins during passage through the animal or processing of the bile. However, since the injected ${ }^{14} \mathrm{C}$ pigments contained $<2 \%$ of these other products, the $33 \%$ of excreted ${ }^{14} \mathrm{C}$ in bilirubin IX $\alpha$ could have derived only from the injected $\left[{ }^{14} \mathrm{C}\right]$ photobilirubin. Against the possibility that the metabolites might have been intermediates in this process are the following observations: (a) only photobilirubins I revert to bilirubin IX $\alpha$ in vitro; (b) excretion of $\left[{ }^{14} \mathrm{C}\right]$ bilirubin was virtually completed within $2 \mathrm{~h}$, yet output of other labeled derivatives, representing approximately one-third of the excreted radioactivity, continued for the remainder of the 24-h period after injection of photobilirubins IA or IB; (c) in studies reported previously (6), injection of ${ }^{14} \mathrm{C}$ labeled photoproducts, isolated from Gunn rat bile during phototherapy, did not augment the excretion of 
bilirubin by recipient Gunn rats. This last observation is also against the possibility that endogenous bilirubin "piggy-backed" into bile in complexes with excreted photoproducts. Moreover, in the present studies, the similarity of the specific activity of the injected photobilirubins and the excreted bilirubin indicates that the latter is derived from the former, and not from the endogenous plasma bilirubin of vastly lower specific activity. The control experiment (Figs. 1 and 2), in which only $\left[{ }^{14} \mathrm{C}\right]$ bilirubin was injected and virtually no $\left[{ }^{14} \mathrm{C}\right]$ bilirubin was excreted, eliminates the contaminating bilirubin IX $\alpha$ as the source of the bilirubin found in bile during the injection of the photobilirubin I preparations.

Of special importance was the demonstration, by appropriate precautions during collection and excretion of the bile, that photobilirubins IA and IB per se were excreted during phototherapy, but were not found in the bile from an unilluminated Gunn rat that was processed simultaneously. These observations support the proposal that these photobilirubins pass into bile before reversion to bilirubin IX $\alpha$. The predicted in vivo stabilization of the photobilirubins IA and IB was evidenced also by the continued appearance of excess bilirubin in the bile for $2-3 \mathrm{~h}$ after the bolus injection of these photoisomers, and the recovery as $\left[{ }^{14} \mathrm{C}\right]$ bilirubin in the bile of two-thirds of the label administered as photobilirubin IA or IB per se. Thus, our experiments suggest strongly that photobilirubins IA and IB are the precursors of the bilirubin IX $\alpha$ that appears in bile during phototherapy, but it is appreciated that some means of prolonged stabilization of the photobilirubins $I$ in pure form is essential to achieve unequivocal documentation of both their in vivo behavior and their structural identification.

Much clearer was our demonstration that, after intravenous administration, the more stable photobilirubin II is excreted in the bile and corresponds to the other major photoproduct (C-9) that appears in the bile of the Gunn rat (6) and human infant (15) during phototherapy. It may correspond also to the " 430 pigment" of Kapitulnik et al. (25). Over half of injected $\left[{ }^{14} \mathrm{C}\right]-$ photobilirubin II was recovered as such in the bile, and virtually none reverted to bilirubin $\mathrm{IX} \alpha, \mathrm{Z}, \mathrm{Z}$ in vivo. Photobilirubin II appeared to serve also as the in vivo precursor of the dihydroxylated bilirubins, C-5, -6 and $-7(2,6)$, presumably via pathways not involving secondary photoreactions, since the recipient Gunn rats were maintained in the dark. Because only C-7 was in part produced from C-9 during extraction procedures, C-5 and C-6 are clearly natural derivatives resulting from biochemical reactions of photobilirubin II. By contrast, C-14, the insoluble brown pigment at the origin of the chromatogram (Table III), is apparently in large part an artefact created by degradation of photobilirubin II during the Folch extraction at low
pH. Since C-5 and C- 6 are found in the bile of unilluminated Gunn rats, but increase during phototherapy, it is probable that photobilirubin II is more susceptible to hydroxylation than the parent bilirubin IX $\alpha, \mathrm{Z}, \mathrm{Z}$. Alternatively, as suggested by McDonagh et al. (16), small amounts of other conformers of bilirubin IX $\alpha, 4 \mathrm{Z}, 15 \mathrm{Z}$ may exist at equilibrium even in the dark, and serve as precursors for the dihydroxybilirubins found in Gunn rats not subjected to phototherapy.

Although each individual experiment was reported in only one or two animals, the major qualitative phenomena were observed in a larger number of animals, including those described here and other rats that received less satisfactory photobilirubin preparations during the developmental stages of this work. Thus, the appearance of bilirubin IX $\alpha$ in bile after administration of irradiated bilirubins or photobilirubins $I$ is reported in five animals, and the excretion of intact photobilirubin II in four animals.

Considered together, all published studies suggest that the photobilirubins are geometric $(\mathrm{Z}, \mathrm{E})$ isomers of bilirubin IX $\alpha$, whose formation may account for the major pathways of bilirubin photocatabolism in the Gunn rat and human neonate. These photoisomers presumably are formed rapidly when light penetrates to the bilirubin deposits in the skin and subcutaneous tissue, then partitioned to the plasma, taken up by the liver, and excreted into the bile. In bile, the thermally unstable photobilirubins IA and IB, believed to be the $\mathrm{E}, \mathrm{Z}$ and $\mathrm{Z}, \mathrm{E}$ isomers, rapidly revert to the $\mathrm{Z}, \mathrm{Z}$ configuration, accounting for the augmented excretion of bilirubin during phototherapy of both Gunn rats (8) and human neonates $(15,26)$. The more stable photobilirubin II remains mostly intact and constitutes the major polar photoproduct, but is in part hydroxylated at the methene bridges, by photo-independent reactions, to yield other minor derivatives. Together, these photoisomerizations and secondary reactions apparently account for $>80 \%$ of the accelerated bilirubin catabolism during phototherapy $(6,15)$.

\section{ACKNOWLEDGMENTS}

The expert technical assistance of Ms. Eileen Hercker and Heidemarie Cheney, and the assistance in manuscript preparation by Ms. Celesta Harvey, are gratefully appreciated.

This work was supported by a Medical Investigator Award from the U. S. Veterans Administration and by research grant AM-14543 from the National Institute of Arthritis, Metabolism, and Digestive Diseases, National Institutes of Health, U. S. Public Health Service.

\section{REFERENCES}

1. McDonagh, A. F. 1971. The role of singlet oxygen in bilirubin photooxidation. Biochem. Biophys. Res. Commun. 44: 1306-1311.

2. Berry, C. S., J. E. Zarembo, and J. D. Ostrow. 1972. Evidence for conversion of bilirubin to dihydroxyl deriva- 
tives in the Gunn rat. Biochem. Biophys. Res. Commun. 49: $1366-1375$.

3. McDonagh, A. F. 1974. The photochemistry and photometabolism of bilirubin. In Phototherapy of the Newborn: An Overview. G. B. Odell, R. Schaffer, and A. P. Simoupoulis, editors. National Academy of Sciences, Washington, D. C. 56-73.

4. Brown, A. K., and J. Showacre. 1976. Phototherapy for Hyperbilirubinemia: Long-Term Implications. NIHNICHHD Interdisciplinary Conference. DHEW Publication NIH-76-1075, Bethesda, Md.

5. Ostrow, J. D. 1972. Photochemical and biochemical basis of the treatment of neonatal jaundice. In Progress in Liver Diseases. H. Popper and F. Schaffner, editors. Grune \& Stratton, Inc., New York. 4: 447-462.

6. Ostrow, J. D., C. S. Berry, and J. E. Zarembo. 1974. Studies on the mechanism of phototherapy in the congenitally jaundiced rat. In Phototherapy of the Newborn: An Overview. G. B. Odell, R. Schaffer, and A. P. Simoupoulis, editors. National Academy of Sciences, Washington, D. C. 74-92.

7. McDonagh, A. F. 1975. Thermal and photochemical reactions of bilirubin IX $\alpha$. Ann. N. Y. Acad. Sci. 244: 553-569.

8. Ostrow, J. D. 1971. Photocatabolism of labelled bilirubin in the congenitally jaundiced (Gunn) rat. J. Clin. Invest. 50: 707-718.

9. Stoll, M. S., E. A. Zenone, J. D. Ostrow, and J. E. Zarembo. 1979. Preparation and properties of bilirubin photoisomers. Biochem. J. 183: 139-146.

10. Onishi, S., S. Itoh, N. Kawade, K. Isobe, and S. Sugiyama. 1979. The separation of configurational isomers of bilirubin by high pressure liquid chromatography and the mechanism of jaundice phototherapy. Biochem. Biophys. Res. Commun. 90: 890-896.

11. Onishi, S., N. Kawade. S. Itoh, K. Isobe, and S. Sugiyama. 1980. High-pressure liquid chromatographic analysis of anaerobic photoproducts of bilirubin IX $\alpha$ in vitro and its comparison with photoproducts in vivo. Biochem. $J$. 190: 527-532.

12. McDonagh, A. F., D. A. Lightner, and T. A. Wooldridge. 1979. Geometric isomerization of bilirubin IX $\alpha$ and its dimethyl ester. J. Chem. Soc. Chem. Commun. 110-112.

13. Lightner, D. A., T. A. Wooldridge, and A. F. McDonagh. 1979. Photobilirubin. An early bilirubin photoproduct detected by absorbance difference spectroscopy. Proc. Natl. Acad. Sci. U. S. A. 76: 29-32.
14. Lightner, D. A., T. A. Wooldridge, and A. F. McDonagh. 1979. Configurational isomerization of bilirubin and the mechanism of jaundice phototherapy. Biochem. Biophys. Res. Commun. 86: 235-243.

15. Onishi, S., K. Isobe, S. Itoh, N. Kawade, and S. Sugiyama. 1980. Demonstration of a geometric isomer of bilirubin IX $\alpha$ in the serum of a hyperbilirubinemic newborn infant, and the mechanism of jaundice phototherapy. Biochem. J. 190: 533-5.36.

16. McDonagh, A. F., L. A. Palma, and D. A. Lightner. 1980. Blue light and bilirubin excretion. Science (Wash. D. C.). 208: 145-151.

17. Ostrow, J. D., L. Hammaker, and R. Schmid. 1961. Preparation of crystalline bilirubin- $\mathrm{C}^{14}$. J. Clin. Invest. 40: $1442-1452$.

18. Bonnett, R., J. E. Davies, M. B. Hursthouse, and G. M. Sheldrick. 1978. The structure of bilirubin. Proc. Roy. Soc. Lond. B. Biol. Sci. 202: 249-268.

19. Michaelsson, M. 1961. Bilirubin determination in serum and urine. Studies on diazo methods and a new copperazo pigment method. Scand. J. Clin. Lab. Invest. 13 (Suppl. 56): 1-80.

20. McDonagh, A. F., and F. Assisi. 1972. The ready isomerization of bilirubin IX $\alpha$ in aqueous solution. Biochem. J. 129: $797-800$.

21. Boonyapisit, S. T., B. W. Trotman, J. D. Ostrow, P. J. Olivieri, and D. Gallo. 1976. Measurement of conjugated and unconjugated bilirubin in bile: a new thin-layer chromatographic method.J. Lab. Clin. Med. 88: 857-863.

22. Schmid, R., and L. Hammaker. 1963. Metabolism and disposition of $\mathrm{C}^{14}$-bilirubin in congenital non-hemolytic jaundice. J. Clin. Invest. 42: 1720-1734.

23. Lightner, D. A. 1977. The photoreactivity of bilirubin and related pyrroles. Photochem. Photobiol. 26: 427-436.

24. Ostrow, J. D., C. S. Berry, R. G. Knodell, and J. E. Zarembo. 1976. Effect of phototherapy on bilirubin excretion in man and the rat. In Bilirubin Metabolism in the Newborn (II). D. Bergsma and S. H. Blondheim, editors. Excerpta Medica, New York. Birth Defects: Original Article Series. 12(2): 81-90.

25. Kapitulnik, J., S. H. Blondheim, A. Grunfeld, and N. A. Kaufmann. 1973. Photodecomposition of bilirubin: ultrafilterable derivatives. Clin. Chim. Acta. 47: 159-166.

26. Lund, H. T., and J. Jacobsen. 1974. Influence of phototherapy on the biliary bilirubin excretion pattern in newborn infants with hyperbilirubemia. J. Pediatr. 85: 262-267. 